\title{
Visual and Analytical Strategies in Spatial Visualization of Junior High School Students in Completing the Reflection Tasks
}

\author{
Faridhotus Sholihah \\ Program Pascasarjana Department of Mathematics \\ Universitas Negeri Surabaya \\ Surabaya, East Java, Indonesia \\ faridhotussholihah16070785024@mhs.unesa.ac.id
}

\author{
Pradnyo Wijayanti, Endah Budi Rahaju \\ Program Pascasarjana Department of Mathematics \\ Universitas Negeri Surabaya \\ Surabaya, East Java, Indonesia \\ Pradnyo_wija@yahoo.com, \\ endah_math_unesa@yahoo.com
}

\begin{abstract}
Spatial visualization is a mental ability in imagining an object, manipulating objects, rotating objects along with changing elements in it, or changing objects described into different shapes. Every student has a different strategy in solving a particular mathematical problem in solving mirroring problems. The strategy used in this research is a visual and analytic strategy. The purpose of this study was to describe the visual and analytical strategies undertaken by students in completing reflection tasks based on spatial visualization mechanisms. Subjects in this study were 3 students of Junior High School from three different grades, 1 female student from grade VII, 1 male student from grade VIII, and 1 female student from grade IX. The subjects were asked to complete the reflection task and continued with the interview to obtain more in-depth data in accordance with the purposes of this study. The reflection task contains commands to reflect lines, plane, and alphabetic letters against lines in the form of horizontal, vertical, and slope symmetry lines. The results of this study indicated that the visual strategy used by the three students was visual mental folding. Although the first and second students are not consistent in using the strategy to complete all assigned tasks. The third student used the strategy consistently. The analytic strategy used by first students was to consider the distance between the object and the symmetry line, whereas second student did not consistently use the analytical strategy by considering distance. The third student maintained the analytic strategy to accomplish all the tasks assign, the analytical strategy by considering equidistance and perpendicularity.
\end{abstract}

Keywords-Spatial Visualization, Visual Strategies, Analytical Strategies Reflection, Geometry.

\section{INTRODUCTION}

The ability of spatial visualization is one of the important or essential abilities students have in learning geometry [1]. This is in accordance with the purpose of learning geometry is that students can think spatially and reasoning about the shape and distance and geometry content specifically [2]. While spatial visualization is one component of spatial [3-5].
Geometry is a part of mathematics that has been taught since elementary school in Indonesia. Reflection is the material that has been taught since elementary school. In reflecting material requires the student's ability to move objects (in this case is mirror) in the right position through mental manipulation.

Turgut and Kondor [6] define spatial visualization as the mental rotation of a three dimensional stimuli. Then $\mathrm{McGee}$ [5] define a spatial visualization as an ability to influence the spatial visualization as an ability to influence the spatial visualization as an abstract object. Clement [7] explains that spatial visualization is the understanding and performing imagined movements of two- and three-dimensional objects. Cakmak and Rogers [8] define spatial visualization as described as the perceptual ability to manipulate a visual image in two- and three-dimensional spaces while spatial orientation refers to the cognitive ability to perceive how one object is positioned relative to other objects in space. While Eryaman [9] explains that spatial visualization refers to the ability to imagine move two- and three-dimensional objects embodied in an image.

Every individual has a strategy different between individuals with each other in the process of spatial visualization of course. But in this study, the strategy is a visual and analytical strategy in spatial visualization. Ramful [10] propose two strategies in spatial visualization: visual strategy and analytic strategy. He further explained that visual strategy is a mental manipulation associated with the shape, location, position, and orientation of an object. While the analytic strategy is a strategy takes into account certain traits or rules according to the mathematical perspective.

Spatial ability can be achieved by using visual strategies, namely strategies that allow individuals to obtain spatial information from the direct perception process. Additionally, spatial ability can also be achieved using analytical strategies. An analytical strategy is a strategy that allows individuals to obtain spatial information without going through visual perception and mental action. Kospentari [11] explain that visual strategy is an initial approach to a geometry that cannot 
be ruled out and only uses analytical strategies because visual strategies cannot be replaced with analytical strategies. It is just that the strategy is used in accordance with the context.

In this study, the assigned task focuses on the reflection of an object on the line of symmetry, so the analytical strategy in question is a strategy with regard to the properties of the reflection as a transformation and the properties that can be used to reflect an object on the line. Ramful [10] explains that visual strategies related to reflection are mental manipulation related to shape, position of object position, and orientation. And then, the analytical strategy in reflection is a strategy used to complete the task of reflection based on characteristics and rules in reflection. There are two properties that are useful for reflecting an object on a symmetrical line, namely: (1) perpendicularity between line segments that connect the points corresponding to objects, images, and symmetry lines and (2) equidistance between objects, symmetry lines and images.

The nature seen in terms of reflection as a transformation is isometric, which is to preserve the jangle, shape and angle. And in this research, properties used are to consider i) perpendicular between the corresponding points on an object with the shadow passing through the symmetry line and ii) the same distance between an object against the symmetry line and the object image to the symmetry line.

\section{METHOD}

This study aims to determine the visual and analytical strategies in spatial visualization in completing the task of reflection. This research used qualitative approach with descriptive research type. Subject in this research were 3 student junior high school. The three students were taken from three different grades of junior high school, namely 1 female student from grade VII, 1 male student from grade VIII, and 1 female student from grade IX. One of which is from Bintang tutoring institution which has similar abilities. On further, grade VII students will be called Subject 1, Grade VIII students are called Subject 2, and grade IX students are called Subject 3. Every subject is required to perform a task related to reflection for 15 minutes. Interview with each subject related to the results of answers was then conducted. Interviews are also intended to explore information related to the strategies the subject uses in spatial visualization upon completion of the reflection task. The collected data is then analyzed. The reflection tasks given in this study was adapted from Ramful, et al [10]. The three tasks ask students to determine the results of the reflection of an object on the symmetry line that has been given (See Figure 1-3).

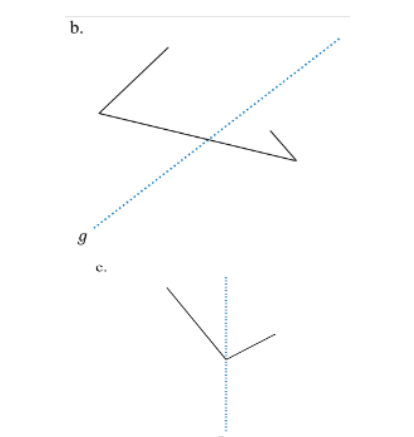

Figure 1: Some Sample Reflection Task 1

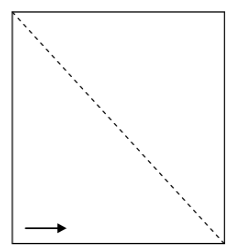

Figure 3. Some Sample Reflection Task 3

\section{RESULT}

Subjects taken in this study were students of the study group so that they came from different schools. The reflection assignment given to the subject contains a question that asks the subject to determine the reflection of a particular object against the given symmetry line. The given symmetry line is not just a horizontal or vertical line, but there is a slash. The task was adapted from Ramful [10]. The issues that will be discussed in this paper is a matter that the majority of research subjects make mistakes in doing it, but all the subject answers of all questions will be observed to know the difficulties encountered and predict what strategies are used by the subject.

\section{A. The Strategy Used by Subject 1}

In the left-hand answer there is no error in reflecting the line given to line $\mathrm{g}$, but if observed more deeply it will be seen that the short-term length of the reflection is not the same length as the reflected line. And the angle formed between the line (object) that will be reflected to the mirror line or symmetry is not the same as the angle formed between the line of reflection to the mirror line.

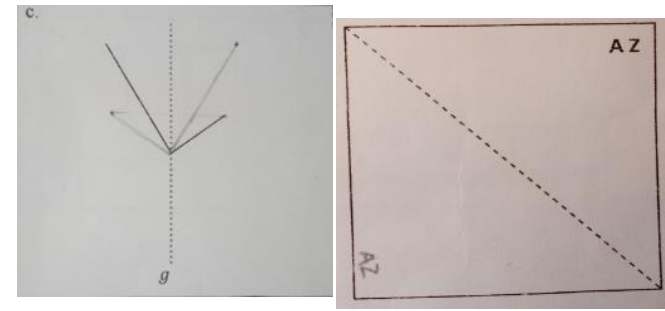

Figure 4: The Answer of Subject 1 in Reflection Task 
When interviewed, Subject 1 explained that when doing some given questions, he first imagine how when the mirror then applied in solving the given problem. This is the first language used Subject 1 to be able to know the picture where the object of reflection object like what. Next, Subject 1 envisioned folding the paper right on the line of symmetry and imagining what reflection results (such as imagining how accurate the shape and position of reflection results). Despite using the strategy, however, it seems difficult to determine the results of the alphabetic mirroring of the symmetry line. After some mental imagining activities, Subject 1 begins to work on the questionnaire provided and explains that Subject 1 used a ruler to know the distance of the object to the symmetry line so that the distance from the mirror can be determined. Although Subject 1 uses a strategy that takes into account a certain distance, it does not consider the other reflection properties of perpendicularity.

\section{B. The Strategy Used by Subject 2}

The visual strategy used by Subject 2 is visual mental folding, though not consistently done by Subject 2 in solving some of the given questions. As seen in the picture the following 2 subject answers show that he does not use mental folding properly. In the left-hand picture shows only draw a straight line from the line to be mirrored. While in the righthand image shows that the subject is less precise in determining the reflection result of the letter "AZ". In this case the subject is wrong in positioning the letters that have been reflection.

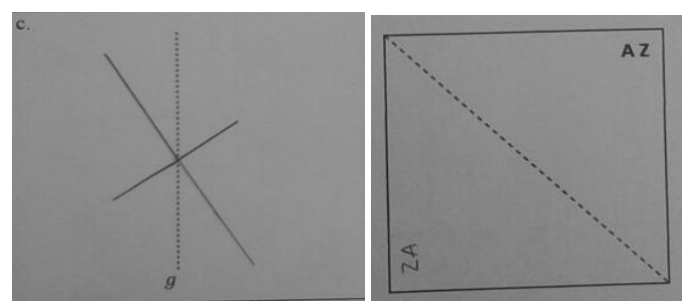

Figure 5: The Answer of Subject 2 in Reflection Task

When interviewing, Subject 2 explains that while working on some given problem, he first imagines how the object in the matter is reflected on the symmetry line. Subject 2 begins to work on it by imagining folding the paper right on the line of symmetry and imagining what reflection results (such as imagining how the shape accuracy and the reflected positioning position). However, Subject 2 is not consistent in doing so because as in the answer in the left above it shows that the reflection generated from the line is to draw the line. After some mental imagining activities, Subject 2 begins to work on the questionnaire provided and explains that he uses a ruler to know the distance of the object to the symmetry line so that the distance from the mirror can be determined. Although Subject 2 uses a strategy taking into account a certain distance, it does not appear to apply it to the problem "c" as the picture above.

\section{The Strategy Used by Subject 3}

Subject 3 accomplishes the task of reflection well. He uses a consistently folding mental strategy in estimating the reflection results of a given object. Only Subject 3 is able to complete the alphabetic mirroring of the given symmetry line correctly.
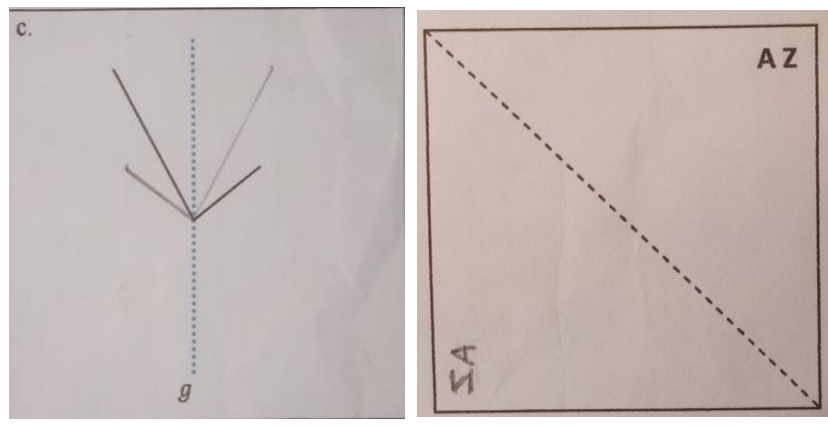

Figure 6: The Answer of Subject 3 in Reflection Task

When interviewed, Subject 3 explains that while working on some given problem, he first imagines how the object in the matter is reflected to the symmetry line. More so he explained that he imagined folding the paper right on the line of symmetry and imagining what kind of mirroring (such as imagining how the shape accuracy and the reflection position). Subject 3 consistently in doing so (mental folding). After the mental imagery to get the reflection of the mirror results, Subject 3 begins to work on the questionnaire provided and explains that he uses a ruler to know the distance of the object to the symmetry line so that the distance from the reflection can be determined. In addition to considering "equidistance", he also considers the nature of "perpendicularity" in solving it.

Subject 1 showed that the visual strategy used in completed the reflection task was visual mental folding. But in some cases, visual mental folding that is done is still not right which results in errors in determining the results of the reflection of the given object. While the analytic strategy used by Subject 1 by using one of the properties she knows related to reflection, namely the distance between points on the object to the symmetry line will be the same as the distance of points on the reflection object to the symmetry line. Unfortunately, Subject 1 did not use perpendicularity properties in determining the results of reflection.

As with subject 1 , subject 2 also used mental folding for visual strategies and uses "equidistance" properties for analytical strategies. However, subject 2 does not consistently do so. Subject 2 has difficulty determining the reflection of an alphabet.

Subject 3 was consistent with the strategy (both visual and analytical strategies) that he uses in completing the reflection task. And subject 3 has applied the perpendicularity.

\section{DISCUSSION}

Visual and analytical strategies are expected to be owned by each individual in spatial visualization. But in this study, visual strategy is the dominant strategy used by students. 
Understanding of reflection and symmetry lines determines the results of the reflection of the subject, because it is not only a visual strategy that is needed. Visual strategy is the first step in estimating the location, shape and orientation of an object.

An understanding of the reflection and the line of symmetry determines the results of the subject's reflection, as it is not just the visual strategy required. Visual strategy is the first step in estimating location, shape, and object orientation. The first student tries to accomplish the task given by using mental folding method although not all tasks can he finish properly. The first student used visual strategy before finding the actual mirror results. Subsequently, the student used one of the properties he knows to be related to reflection, the distance between the points on the object to the symmetry line will be equal to the distance of the points on the reflected object to the symmetry line. The first student did not use the nature of "perpendicularity" in determining the mirror results. The second student also used the same strategy used in the first student, but the second student did not consistently use it. The third student that is consistent with the strategy he uses in completing the reflection task.

\section{CONCLUSION}

Based on the findings, that visual strategy used by the students was visual mental folding. Although some student are not consistent in used the strategy to complete all assigned tasks. The analytic strategy used by the students was to consider the distance between the object and the symmetry line, whereas second students not consistently use the analytic strategy by considering distance. The third student maintains the analytic strategy used to accomplish the task assign, the analytical strategy by considering equidistance and perpendicularity.

\section{ACKNOWLEDGMENT}

This research reported in this paper is supported by Bintang Tutoring Institutions which has provided the opportunity for researchers to conduct research at the institution.

\section{REFERENCES}

[1] A. H. Abdullah, "Case Study on Visual Spatial Skills and Level of Geometric Thinking in Learning 3D Geometry Among High Achievers", Research Gate: Man In India, vol. 96 no. 1-2, pp. 489499, 2015

[2] J. A. V. de Walle Elementary And Middle School Mathematics: Teaching Developmentally, Pearson Education, 2013.

[3] Ahmad and A. Jaelani, "Kemampuan Spasial: Apa dan Bagaimana Cara Meningkatkannya?", Jurnal Pendidikan Nusantara Indonesia, vol. 1, no. 1, p. 1, 2015.

[4] A. Baki, T. Kosa, and T. Guven, "A comparative study of the effects of using dynamic geometry software and physical manipulatives on the spatial visualisation skills of pre-service mathematics teachers", British Journal of Educational Technology, vol. 42, no. 2, pp. 291310, 2011.
[5] M. G. McGee, "Human Spatial Abilities: Psychometric Studies and Environmental, Genetic, Hormonal, and Neurological Influences", Psychological Bulletin, vol. 86, no. 5, pp. 889-918, 1979.

[6] M. Turgut and R. N. Kondor, "Spatial Visualization Skills of Hungarian and Turkish Prospective Mathematics Teachers", International Journal for Studies in Mathematics Education, vol. 6, no. 1 , pp. 168-183, 2013.

[7] D. H. Clements, Geometric and Spatial Thinking in Young Children, National Science Foundation, Arlington, VA, 1998.

[8] P. Akayuure, S. K. Asiedu-Addo, and V. Alebana, "Investigating the Effect of Origami Instruction on Pre-service Teachers' Spatial Ability and Geometric Knowledge for Teaching", International Journal of Education in Mathematics, Science and Technology (IJEMST), vol. 4, no. 3, pp. 198-209, 2016.

[9] Z. Eryaman, A Study On Sixth Grade Students' Spatial Reasoning Regarding 2d Representations Of 3d Objects (Thesis), Retrieved from (https://etd.lib.metu.edu.tr/upload/3/12611378/index.pdf), 2009.

[10] A. Ramful, S. Y. Ho, and T. Lowrie, "Visual And Analytical Strategies In Spatial Visualisation: Perspectives From Bilateral Symmetry And Reflection", Mathematics Education Research Group of Australasia, Inc, 2015.

[11] G. Kospentaris, "Visual and Analytic Strategies in Geometry", Frontline Learning Research, vol. 4, no. 1, 2006. 